\title{
Means to Enhance the Production of Water from Solar Thermal Pasteurization System
}

\author{
Tri Ratna Bajracharya ${ }^{1,}$ Anil Kunwar ${ }^{2}$
}

${ }^{1}$ Director, Center for Energy Studies, Institute of Engineering

${ }^{2}$ Mechanical Engineer, Nepal Bureau of Standards and Metrology

\begin{abstract}
A density driven solar thermal pasteurization system has been installed for the purpose of purification of water. The main components of this system are evacuated tube collectors with heat pipe, convection tube, holding tube, insulation system, heat exchanger and supply tank. The daily volume of water produced from the system as the pasteurized output reached its maximum value of 4 litres as measured in the days of first two weeks of February, 2011. The main parameters affecting the production rate of water considered are amount of solar insolation falling on the collector area during the peak 3 sunshine hours, mean temperature of water in the heat exchanger and the diameter of the pipe used in the convection tube. It has been known that the daily production volume of water increases with the higher values of solar insolation and the mean temperature of the heat exchanger whereas diameter of the tube used in the convection loop should be smaller to produce more water at the output.
\end{abstract}

\section{Introduction}

Drinking water crisis is an alarming problem in the world and there is always a need of an appropriate system to address this problem. In developing countries the use of renewable energy technology to purify the water and make it potable can help greatly be beneficial. Using solar thermal technology for pasteurization of water can be a good option for purification of water.

A density driven solar thermal pasteurization system was fabricated with components as shown in figure 1.1. The main components of the system are Evacuated Tube Collector with heat pipe, convection loop, holding tube, insulation system, heat exchanger and supply tank. Evacuated tube collectors(ETC) consisting of 18 glass tubes each of outer diameter of $58 \mathrm{~mm}$ and length $1800 \mathrm{~mm}$ was used for the system. The insulated heat pipe for this ETC was with the hydraulic diameter of $13.48 \mathrm{~cm}$. Galvanized Iron(GI0 pipes of $20 \mathrm{~mm}$ diameter was used for convection tube, holding tube and rest of the piping system the piping system. Thermocole with thermal conductivity of $0.039 \mathrm{~W} / \mathrm{m} \mathrm{K}$ was used for insulating the pipes of convection tube and the holding tube. The intersection of the top portion of the convection tube and the pipe leading to holding tube was $127 \mathrm{~cm}$ vertically above the collector heat pipe. The holding tube was $9 \mathrm{~cm}$ vertically above the intersection and this was selected on the basis of the height reached by a given mass of water in pipe due to the increase of its volume at lower density at elevated temperature. Remarkably, the elevation of the water level in the supply tank should be at the same level of the intersection point in order to allow free circulation of water in convection tube. 
The heat exchanger for the system consists of a coiled copper tube of $15 \mathrm{~mm}$ diameter surrounded by a mild steel insulated tank of $27 \mathrm{~cm}$ diameter and $77 \mathrm{~cm}$ height.

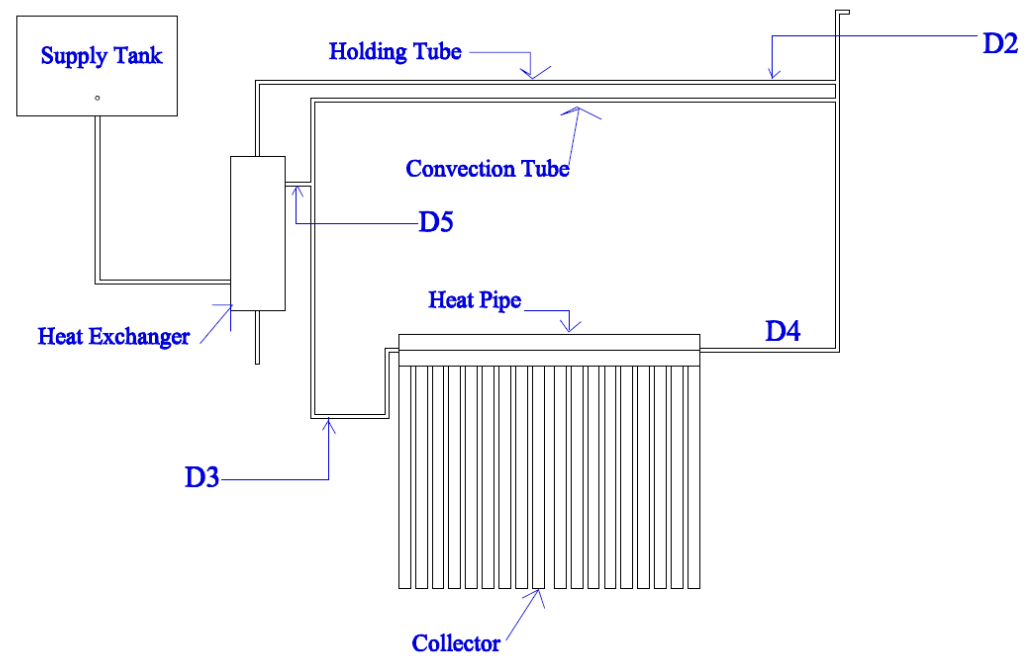

Figure 1: Schematic Diagram showing Components of Solar Thermal Pasteurization System for Water

A given mass of water is first supplied to the supply tank which flows down to the heat exchanger tank and further down to the collector heat pipe thereby filling the convection tube. The incoming solar irradiation heats the fluid inside the collector which subsequently rises on the top of the collector glass tubes and transfers its heat to the water in the heat pipe. The water in the heat pipe having elevated temperature becomes less dense and rises up in the convection tube, the space of the heat pipe being replaced by the colder and denser water previously in the upper portion of the convection tube. This process continues on till all the water in the convection tube reaches a high temperature of $65-75{ }^{\circ} \mathrm{C}$ and maintains isothermal condition owing to the heavy insulation of heat pipe and the GI tubes. Then the additional heat transfer from the collector fluid to the water in vicinity causes it to be even less dense. This water trying to rise up causes some water from the convection loop to be lifted up in the holding tube. The space is immediatedly filled by the flowing water from the supply tank. The water reaching the holding tube stays for a sufficient time in an elevated temperature of 70 degree celsius or more as a result of which even the most thermally resistant microbial organism gets inactivated. This water leaving the holding tube passes inside the copper tube of the heat exchanger and is cooled down while coming from exit after transferring its heat to the water surrounding the tube.

The major parameters of study for this device are temperatures at different locations of the system, solar irradiance falling on the collector and daily volumetric production from the system. Being further more specific, the study was done mainly on the factors that affect the volumetric production from the system. On the observations made from January 27 to February 15 in 2007, the highest volume of pasteurized water obtained from the system in a day was about 4 litres. It is 
greatly essential that the daily production from the system should be increased. The main factors that affect the output volume from the system are outlined as following:

- Amount of Solar Irradiance falling on the collector

- Mean temperature of water at heat exchanger

- Diameter of the pipe as used in the convection loop

\section{Effect of Solar Irradiance on the Amount of Water Pasteurized}

The solar irradiance values have been measured for 6 days from 10 AM to 3 PM. Similarly the total volume of water pasteurized was also measured each day. Having noticed that the irradiance below $600 \mathrm{~W} / \mathrm{m}^{2}$ has no significant effect on volumetric production, the values for 3 peak sun hours in a day were used for calculation of effective solar insolation responsible for daily volumetric production.

The following table 1 shows the data taken on 6 days between $22^{\text {nd }}$ Magh to $2^{\text {nd }}$ Falgun, 2067. Herein it is assumed that the variation of irradiance with time follows the quadratic curve fitting pattern. Figure 2 shows the pattern of irradiance on 3 peak sunshine hours for Magh 24, Monday.

Table 1: Solar Irradiance Values in W/m $\mathrm{m}^{2}$ and Daily Volumetric Production in Litres

\begin{tabular}{|c|c|c|c|c|c|c|c|c|c|c|c|}
\hline \multicolumn{2}{|c|}{ Magh 22 } & \multicolumn{2}{c|}{ Magh 23 } & \multicolumn{2}{c|}{ Magh 24 } & \multicolumn{2}{c|}{ Magh 25 } & \multicolumn{2}{c|}{ Magh 26 } & \multicolumn{2}{c|}{ Magh 27 } \\
\hline Time & Irrad. & Time & Irrad & Time & Irrad & Time & Irrad & Time & Irrad & Time & Irrad \\
\hline $11: 00$ & 620 & $11: 00$ & 560 & $11: 30$ & 680 & $11: 30$ & 680 & $11: 30$ & 600 & $11: 30$ & 620 \\
\hline $11: 10$ & 620 & $11: 10$ & 580 & $11: 40$ & 700 & $11: 40$ & 700 & $11: 40$ & 580 & $11: 40$ & 700 \\
\hline & & $11: 20$ & 600 & $11: 50$ & 700 & $11: 50$ & 720 & $11: 50$ & 620 & $11: 50$ & 680 \\
\hline & & $11: 30$ & 580 & $12: 00$ & 700 & $12: 00$ & 760 & $12: 00$ & 660 & $12: 00$ & 700 \\
\hline & & $11: 40$ & 660 & $12: 10$ & 780 & $12: 10$ & 800 & $12: 10$ & 640 & $12: 10$ & 800 \\
\hline $11: 50$ & 680 & $11: 50$ & 660 & $12: 20$ & 800 & $12: 20$ & 800 & $12: 20$ & 660 & $12: 20$ & 780 \\
\hline $12: 00$ & 700 & $12: 00$ & 680 & $12: 30$ & 800 & $12: 30$ & 820 & $12: 30$ & 700 & $12: 30$ & 820 \\
\hline & & $12: 10$ & 680 & $12: 40$ & 900 & $12: 40$ & 860 & $12: 40$ & 700 & $12: 40$ & 860 \\
\hline & & $12: 20$ & 700 & $12: 50$ & 900 & $12: 50$ & 860 & $12: 50$ & 780 & $12: 50$ & 880 \\
\hline $12: 30$ & 800 & $12: 30$ & 720 & $13: 00$ & 900 & $13: 00$ & 920 & $13: 00$ & 740 & $13: 00$ & 900 \\
\hline & & $12: 40$ & 720 & $13: 10$ & 920 & $13: 10$ & 960 & $13: 10$ & 120 & $13: 10$ & 900 \\
\hline $12: 50$ & 780 & $12: 50$ & 700 & $13: 20$ & 900 & $13: 20$ & 920 & $13: 20$ & 800 & $13: 20$ & 900 \\
\hline $13: 00$ & 780 & $13: 00$ & 700 & $13: 30$ & 900 & $13: 30$ & 920 & $13: 30$ & 800 & $13: 30$ & 880 \\
\hline $13: 10$ & 800 & $13: 10$ & 680 & $13: 40$ & 880 & $13: 40$ & 900 & $13: 40$ & 780 & $13: 40$ & 880 \\
\hline & & $13: 20$ & 680 & $13: 50$ & 840 & $13: 50$ & 920 & $13: 50$ & 700 & $13: 50$ & 840 \\
\hline & & $13: 30$ & 660 & $14: 00$ & 760 & $14: 00$ & 860 & $14: 00$ & 680 & $14: 00$ & 840 \\
\hline $13: 40$ & 680 & $13: 40$ & 620 & $14: 10$ & 760 & $14: 10$ & 800 & $14: 10$ & 760 & $14: 10$ & 820 \\
\hline $13: 50$ & 700 & $13: 50$ & 640 & $14: 20$ & 700 & $14: 20$ & 740 & $14: 20$ & 520 & $14: 20$ & 780 \\
\hline $14: 00$ & 640 & $14: 00$ & 640 & $14: 30$ & 700 & $14: 30$ & 680 & $14: 30$ & 640 & $14: 30$ & 720 \\
\hline & & & & & & & & & & & \\
\hline Dly. Volm & 2.715 & & 1.21 & & 3.494 & & 4.059 & & 2.4461 & & 2.37 \\
\hline
\end{tabular}




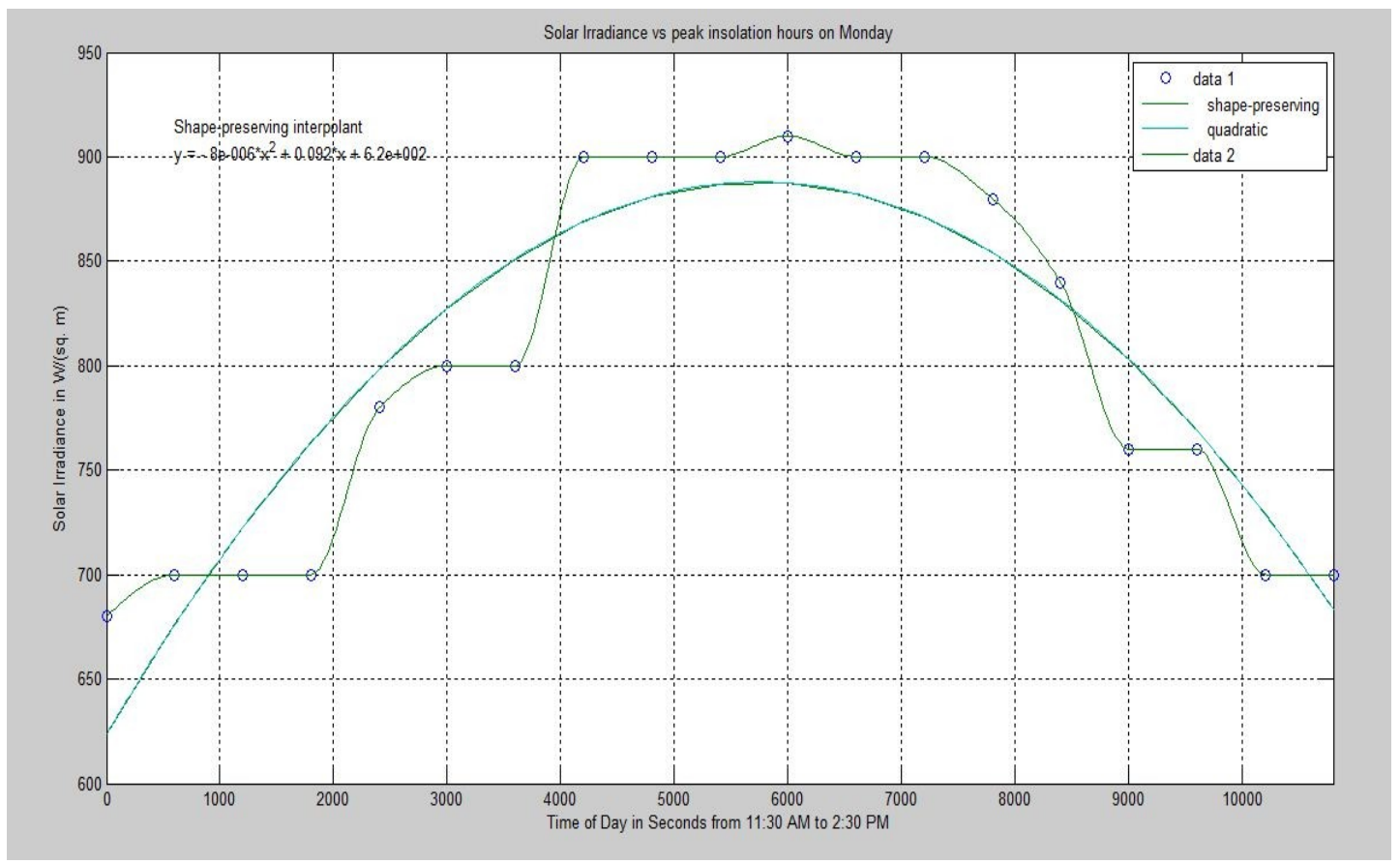

Figure 2: Irradiance pattern for 3 Peak Sunshine Hours on Magh 24, Monday

The values corresponding to 3 peak sunshine hours have been integrated with time using MATLAB. The relation between Solar Insolation in $\mathrm{kW} \mathrm{h} / \mathrm{m}^{2}$ per 3 peak sun hours and daily volumetric production has been deduced below using the same software. Table 2 and illustrates the correlation between these two quantities.

Table 3: Solar Insolation for 3 Peak Sun Hours and Daily Production on different Days

\begin{tabular}{|l|c|c|}
\hline \multicolumn{1}{|c|}{ Date } & Solar Insolation $\left(\mathrm{kW} \mathrm{h} / \mathrm{m}^{2}\right)$ & Daily Production (litres) \\
\hline Magh 22, Saturday & 2.145 & 2.715 \\
\hline Magh 23, Sunday & 1.9805 & 1.21 \\
\hline Magh 24, Monday & 2.4266 & 3.494 \\
\hline Magh 25, Tuesday & 2.4918 & 4.059 \\
\hline Magh 26, Wednesday & 1.9777 & 2.4461 \\
\hline Falgun 2, Monday & 2.4381 & 2.37 \\
\hline
\end{tabular}

These values have been plotted on the graph and the least square cubic curve has been drawn as shown in figure 3. If $\mathrm{G}$ is the solar insolation for 3 peak sunshine hours in a day in $\mathrm{kW} \mathrm{h} / \mathrm{m}^{2}$ and $\mathrm{V}$ be the total volume of water produced in a day in litres, the relating equation between $\mathrm{G}$ and $\mathrm{V}$ was obtained as follow:

$$
\mathrm{V}=105.22 \mathrm{G}^{3}-699.25 \mathrm{G}^{2}+1546.1 \mathrm{G}-1134.8
$$

To check the reliability of this equation the solar irradiation data taken on 27 March 2002 by Duff et. al were used for determining the 3 Peak sunshine hours insolation with MATLAB. The 
insolation for 3 Peak Irradiance Hours was obtained as $2.8484 \mathrm{~kW} \mathrm{~h} / \mathrm{m}^{2}$. Using this value in the above equation, the volume of water pasteurized is obtained as 27.5 litres. In the real condition then, the volume of water pasteurized for 3 peak irradiance hours was obtained as 49.7 litres by Duff et. al. This verifies that the trend shown by this equation is correct. The difference between these two volumes is due to the physical variabilities of the systems used there and here and also due to error in manipulating the data while determining the solar insolation and relation between $\mathrm{V}$ and G. More data needs to considered while deriving the relation between physical quantities.

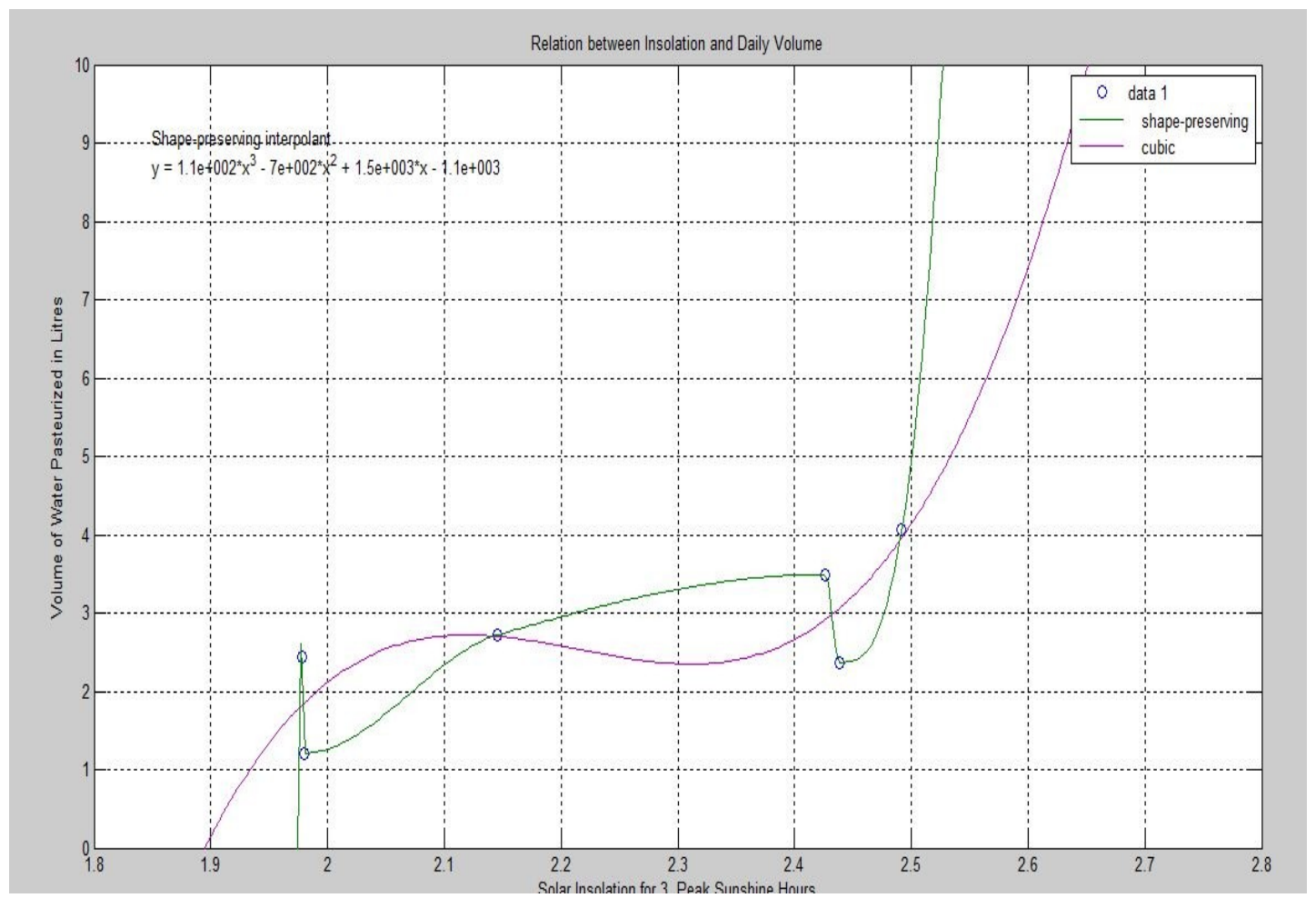

Figure 3: Plot of Daily Production Volume in Litres as a function of Solar Insolation for Peak Sunshine Hours

Thus, it can be generalized that the daily production volume of pasteurized water increases with increased effective insolation. The amount of increased solar flux not only gives more heat to the collector area but also sends more amount of water in the holding tube thereby increasing the mean temperature of water inside the holding tube. From table 1 and 2, it can be noted that the peak irradiance value and its persistence period is greatly responsible for increased production even in the case of same insolation. The daily production will be more in summer. Finally, the cloudy condition and shading effect decreases the insolation value and thereby the production of water.

\section{Effect of Mean Temperature of Water inside Heat Exchanger}

After the water in the convection tube rises up in the holding tube, it is replaced by the water coming from the heat exchanger. And if the water coming from heat exchanger exit is initially at a raised temperature, less amount of heat energy is required for it to reach the pasteurization 
temperature. And this increases the rate of rise of water up in the holding tube and thereby the daily production. Moreover, the raised mean temperature of the water in the heat exchanger reduces the heat transfer to the water mass there. Thus, it is emphasized that the mean temperature of the heat exchanger should be raised. Figure 4 shows the temperature profile of the water at the heat exchanger exit as measured by D5 thermometer as on Magh 13. Here it can be noticed that the water reaches the temperature above $60{ }^{\circ} \mathrm{C}$ only from 12 noon. This justifies the cause of delay in rise of water in the holding tube (The production starts generally after noon in winter). If this temperature was reached before $11 \mathrm{AM}$ owing to the initially raised mean temperature of heat exchanger, the production would start before noon and the daily production would be high.

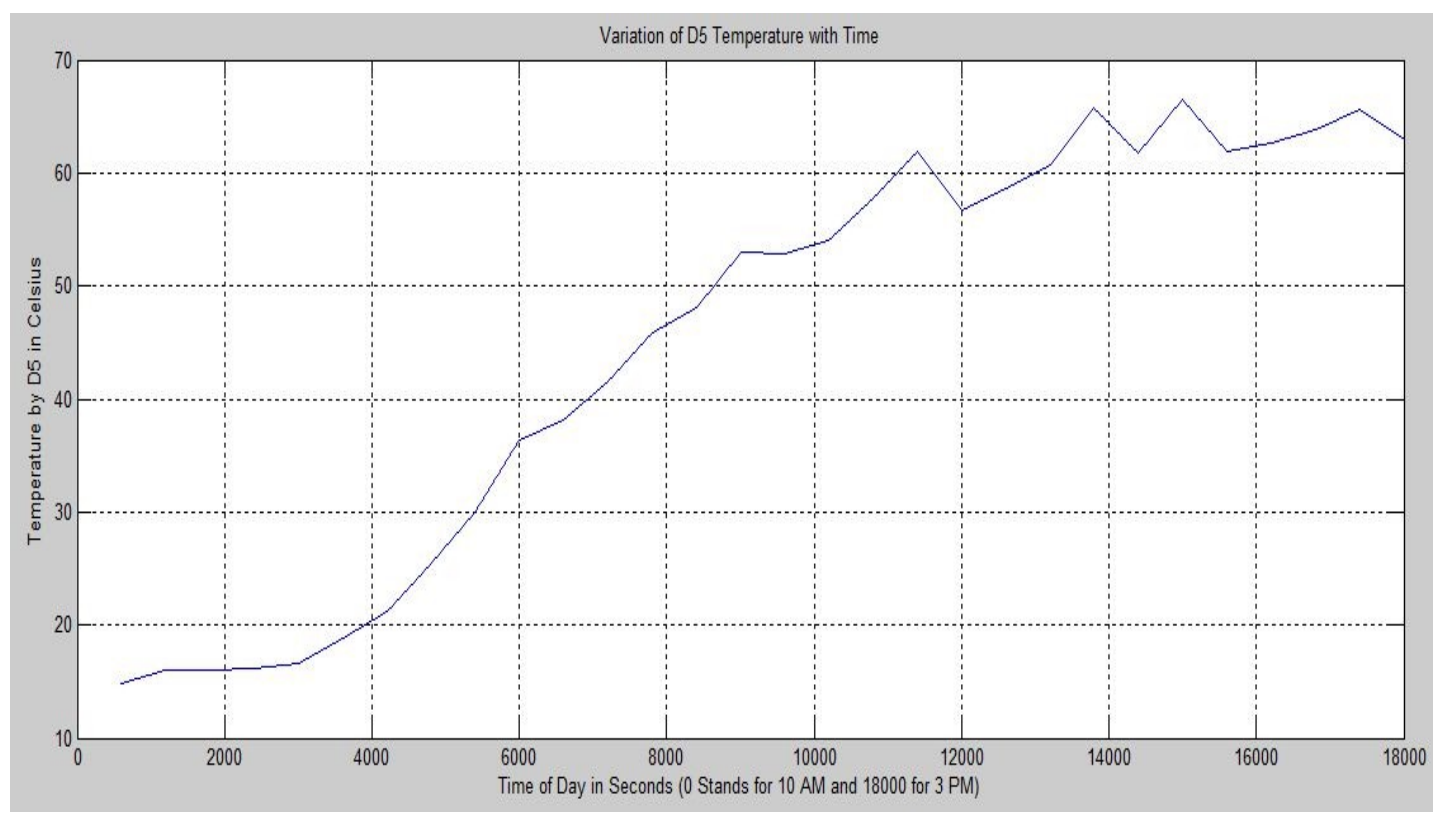

Figure 4: Temperature Profile of Water at the Heat Exchanger Exit (D5)

In summer days, the mean temperature at heat exchanger tank of this size will be raised enough owing to the high solar insolation. In winter days, since the insolation is low the heat exchanger tank to be used should be of smaller diameter (say less than half) so that less heat can be sufficient to heat the smaller volume of water then.

\section{Effect of Diameter of the Pipe as used in the convection loop}

Initially, this effect was not considered. But when the experiment of convection tube with Evacuated Tube Collectors with attached storage tank (shown in figure 5 below) failed to produce rise of water in the holding tube, it was considered important in determining the effect of tube diameter on the heat transfer coefficient of water. Notably, the evacuated tube collectors with heat pipe (of smaller hydraulic diameter as shown in figure 6) has caused the water production rate and thereby supporting the relation between diameter and water production rate. 


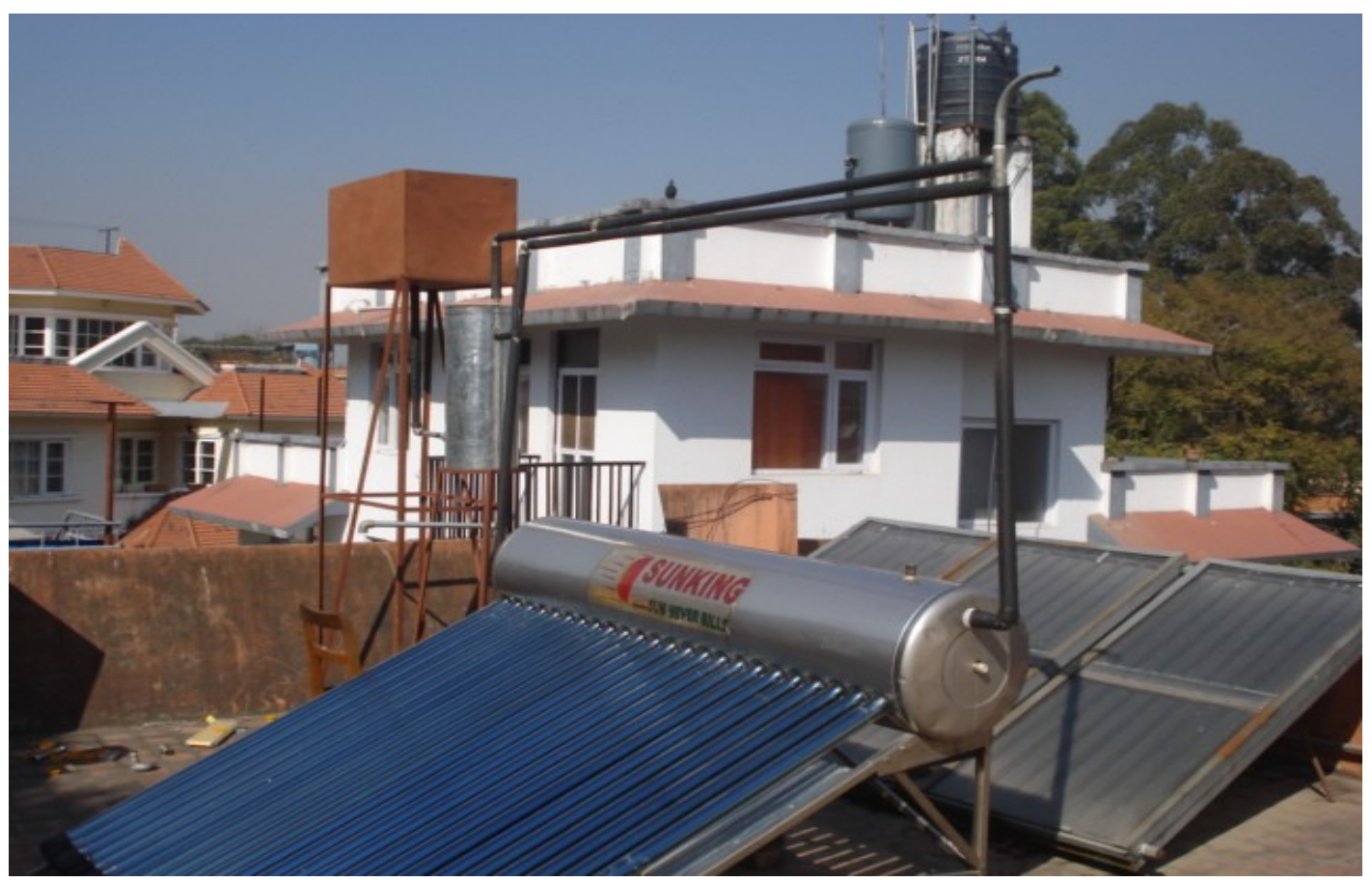

Figure 5: System having Evacuated Tube Collector with attached storage tank of $40 \mathrm{~cm}$ diameter

A MATLAB program was developed to determine the convection heat transfer coefficient of water using its thermophysical properties. This program was used to plot a graph showing the variation of convection heat transfer coefficient(h) of water inside the circular tube with the diameter of the tube. The graph as shown in figure 7 illustrates that the value of $\mathrm{h}$ decreases drastically when the diameter of pipe used is increased from $10 \mathrm{~mm}$ to $20 \mathrm{~mm}$. Thus it can be inferred that the heat exchange rate within the water increases with lower diameter. The production can be increased when the GI tube used in the convection loop can be replaced by pipe of smaller diameter. 


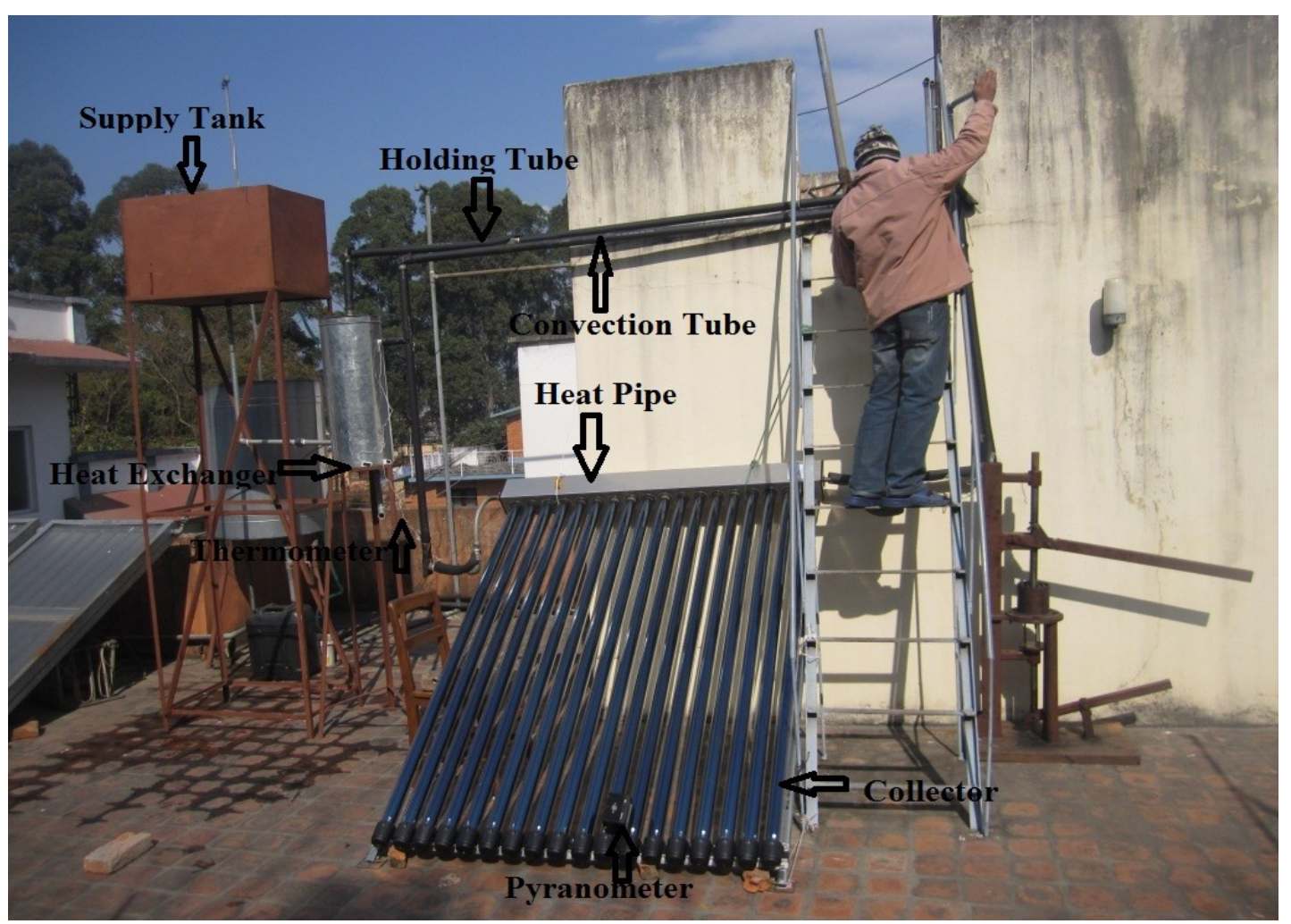

Figure 6: System having Evacuated Tube Collector with heat pipe of hydraulic diameter of $13.48 \mathrm{~cm}$

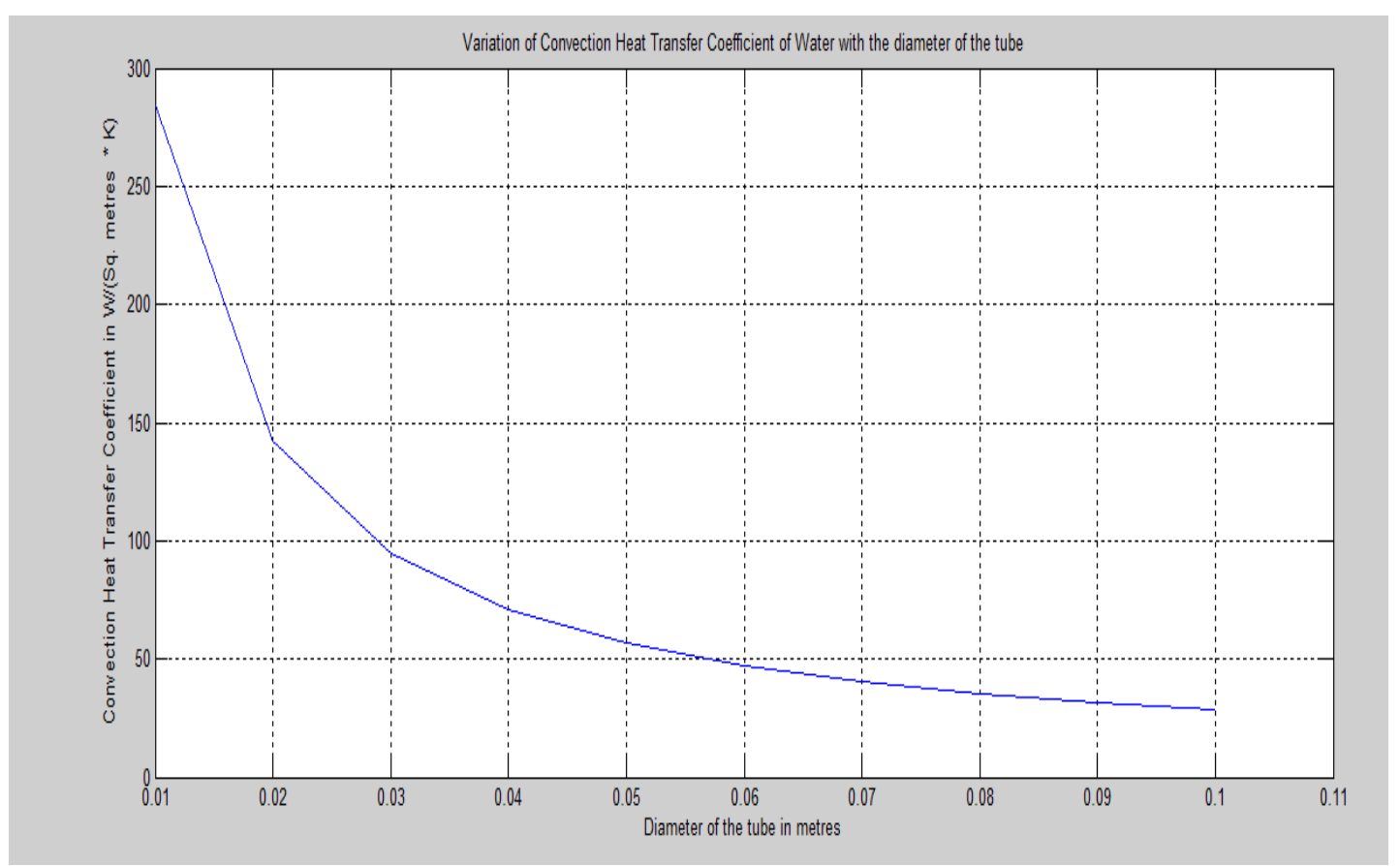

Figure 7: Graph of $h$ versus diameter of a tube 


\section{Conclusion}

Solar thermal pasteurization technology as applied to the purification of water can be a good solution for reduction of drinking water crisis. A density driven solar thermal pasteurization system consisting of evacuated tube collectors with heat pipe, heat exchanger, convection tube, holding tube, insulation system and suppy tank was installed. In the measurement of volumetric productions from the system as done on the days of February, the highest volume was 4 litres per day. Amount of solar insolation, mean temperature of the water in the heat exchanger and the diameter of the size of the pipe used in the convection loop were considered as the major parameters affective the production of pasteurized water. The daily production of water increases with the increase of effective solar insolation and a third degree polynomial best describes the variation of volume as a function of solar insolation for 3 peak sunshine hours. More data needs to be considered for drawing stronger conclusion on this matter. The initially raised mean temperature of heat exchange reduces heat loss to the heat exchanger on one hand whereas accelerates the rate of increase of temperature of water present in the convection tube thereby increasing the volumetric output. Finally, it has been determined that the convection heat transfer coefficient of a fluid flowing in a tube decreases with the increase of diameter of the tube. Thus use of circular tubes of diameter smaller than that used in the existing system for the convection tube can enhance the heat exchange rate within the water and thus increase the production rate of pasteurized water.

\section{REFERENCES}

[1] Duff W.S. and Hodgson D. A., 2005, “A Simple High Efficiency Solar Water Purification System", Solar Energy, Vol. 79, pp. 25-32

[2] Hunt B. R., Lipsman R. L. and Rosenberg J.M., 2002," A Guide to MATLAB for Beginners and Experienced Users", First South Asian Edition, Cambridge University Press

[3] Incropera F. P. and Dewitt D.P., 1990, "Fundamentals of Heat and Mass Transfer", Third Edition, John Wiley and Sons, Inc

[4] Kunwar A., 2011, "Solar Thermal Pasteurization System for Purification of Water", M.Sc. Thesis, Department of Mechanical Engineering, Pulchowk Campus, Institute of Engineering, Tribhuvan University, Lalitpur, Nepal

[5] Ozisik M.N., 1985, “ Heat Transfer A Basic Approach”, First Edition, McGraw Hill International Editions

[6] Sulaiman F. and Singh B.S.M.,2003," Simulation of Convective Heat Transfer Coefficient in the Receiver Tube of a Parabolic Trough Concentrator", Advanced Technology Congress, Putrajaya 